\title{
$\theta$ OPEN ACCESS \\ Football for life versus antidoping for the masses: ethical antidoping issues and solutions based on the extenuating experiences of an elite footballer competing while undergoing treatment for metastatic testicular cancer
}

\author{
Richard Weiler, ${ }^{1}{ }^{1,3}$ Dylan Tombides, ${ }^{1}$ Jon Urwin, ${ }^{1}$ Jane Clarke, ${ }^{4}$ Michele Verroken ${ }^{5}$
}

\begin{abstract}
${ }^{1}$ West Ham United Football Club Training Ground, Chadwell Heath, Essex, UK ${ }^{2}$ University College London Hospitals NHS Foundation Trust, London, UK ${ }^{3}$ The FA Centre for Disability Football Research, BurtonUpon-Trent, England ${ }^{4} 148$ Harley Street, London, UK

${ }^{5}$ Sporting Integrity Ltd, Bishopstone, Aylesbury, Buckinghamshire, UK
\end{abstract}

Correspondence to Dr Richard Weiler, University College London Hospitals NHS Foundation Trust,235 Euston Road, London NW1 2BU, UK; rweiler@doctors.org.uk

Accepted 25 February 2014 Published Online First 25 March 2014

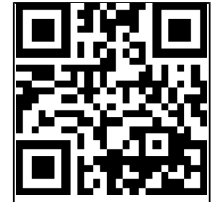

Open Access Scan to access mo free content

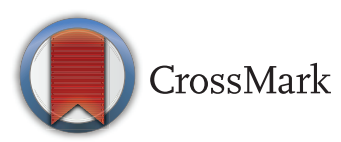

To cite: Weiler $R$, Tombides D, Urwin J, et al. $\mathrm{Br} J$ Sports Med 2014;48:814-816.

\begin{abstract}
It is thankfully rare for extenuating circumstances to fully test the processes and procedures enshrined in national and world antidoping authorities' rules and laws. It is also thankfully very rare that a failed drugs test can have some positive implications. Antidoping laws are undoubtedly focused on ensuring fair competition, however, there are occasions when honest athletes discover medical diagnoses through failed antidoping tests. The purpose of this paper is to broadly discuss antidoping considerations encountered, based on the four principles of medical ethics and to propose simple solutions to these problems. Unfortunately, extreme medical circumstances will often test the limits of antidoping and medical processes and with open channels for feedback, these systems can improve. Performance enhancement seems an illogical concept if an athlete's medical treatment and disease are more inherently performance harming than unintended potential doping, but needs to be carefully managed to maintain fair sport.
\end{abstract}

\section{INTRODUCTION}

It is thankfully rare for extenuating circumstances to fully test the processes and procedures enshrined in national and world antidoping authorities' rules and laws. It is also thankfully very rare that a failed drugs test can have some positive implications. Antidoping laws are undoubtedly focused on ensuring fair competition, however, there are occasions, when honest athletes discover medical diagnoses through failed antidoping tests. The relevant sporting bodies must do everything they can to try and ensure that difficult medical circumstances are swiftly communicated to an athlete and sympathetically managed, rather than attempting to first process an antidoping rule violation and seeking medical assistance second.

However, an athlete choosing to continue in elite sporting competition in spite of a cancer diagnosis, complex medications and treatments, may face ethical and antidoping procedural challenges. Competitive sport requires regular physical activity with a huge array of physical and psychological benefits, associated with and resulting from cardiorespiratory fitness, which will benefit athletes in these situations. ${ }^{1-3}$ The benefits of regular physical activity for people living with cancer and undergoing chemotherapy are considerable, leading to improved clinical outcomes and better quality of life. ${ }^{3}$ When FIFA first coined the terms 'Football for Health' and 'Football for Hope' they may not necessarily have expected such literal sporting applicability for a professional footballer, for whom health and psychological benefits can be easily forgotten, with performance the over-riding elite sport goal. ${ }^{5}$ FIFA and the IOC have demonstrated support and commitment for the promotion of health and well-being through regular physical activity and sport. ${ }^{78}$

An abstract of this paper was submitted to and selected for presentation at the WADA and FIFA antidoping consensus meeting hosted by FIFA, in Zürich, Switzerland on 29 November 2013, in the hope that one athlete's unique experiences following a diagnosis of testicular cancer through a failed antidoping test would help others in this unfortunate position in the future. Dylan Tombides (DT), a co-author on this paper, failed an antidoping test with a raised human chorionic gonadotropin (hCG) at the FIFA U17 World Cup in Mexico in 2011. The FIFA Chief Medical Officer, without any delay contacted the national team physician, recommending a specialised examination, as the results signalled the diagnosis and start of a battle against metastatic testicular cancer. Since then DT has had numerous episodes of chemotherapy, stem cell transplants, radiotherapy, complementary and alternative therapy, vascular and major abdominal surgery. DT has also defied a series of hugely challenging and complex fitness battles in his wish to remain available for selection, and having gained his West Ham United Football Club first team debut in 2013, played many games in the 2013/ 2014 season and competed for the Australia U22 Football Team at the Asian Federation Cup in Oman in January 2014-all the while undergoing chemotherapy or having very recently recovered from major procedures.

hCG was first prohibited in sport during the 1980s. ${ }^{9}$ hCG is a glycoprotein, which when administered can increase the endogenous production of testosterone, without increasing the testosterone to epitestosterone ratio and can be increased after misuse of anabolic-androgenic steroids. ${ }^{9}$

There are reports in the press of athletes being diagnosed with testicular cancer as a result of high hCG concentrations being detected during routine doping control tests, but the actual numbers of 
such events have not yet been published or made public. The WADA statistics 2012 reports 93 adverse analytical findings for hCG, however it is not known how many of those are due to doping or as a result of disease. ${ }^{10}$

The purpose of this paper is to broadly discuss antidoping considerations encountered, based on the four principles of medical ethics and to propose simple solutions to these problems. ${ }^{11} 12$ Unfortunately, extreme medical circumstances will often test the limits of antidoping and medical processes and with open channels for feedback, these systems can improve. Performance enhancement seems an illogical concept if an athlete's medical treatment and disease are more inherently performance harming than unintended potential doping, but needs to be carefully managed to maintain fair sport.

\section{SUMMARY OF ISSUES AND SOLUTIONS RELATING TO THE FOUR PILLARS OF MEDICAL ETHICS Autonomy}

If an athlete in extreme medical circumstances is able to and wishes to continue competing in his/her chosen sport, it is possible that rigid application of antidoping rules may hamper athlete autonomy. For example, prolonged dexamethasone administration during chemotherapy for metastatic cancer should not be suggested to mandate a period of exclusion from competitive sport in accordance with strict adherence to antidoping rules. Processes should ensure that in these circumstances such challenges to an athlete's autonomy are universally avoided by national antidoping organisations and international sporting federations.

Initial disease diagnosis from antidoping tests should always be promptly and sympathetically communicated to an athlete, rather than an 'atypical finding' being recorded. Communication channels with international antidoping authorities for an athlete's medical professionals, in these extenuating circumstances need to remain open and be clearly defined. When medical treatment decisions and related antidoping queries are potentially challenged, medical professionals should be able to communicate directly with national or world antidoping authority medical experts for advice and guidance. This would ensure the avoidance of standard rigid procedural discussions and avoid challenges to patient autonomy and medical ethics. Communication channels with antidoping administrative staff on complex medical matters pose challenges for all concerned, ultimately reducing patient autonomy and causing unnecessary athlete stress. The contact details for these communication channels in extreme circumstances between medical professionals should be clear, well-publicised and perhaps made readily available on national and WADA websites.

When medical staff and athletes are unaware of consumed agents or provenance of such agents as part of medical care (eg, solvents for chemotherapeutic agents or contamination risk of supplements), reasonable concessions should be promptly made by medical antidoping experts, where performance enhancement is clearly not possible. While a potential solution can be found in assurances of retrospective therapeutic use exemption (TUE) approval for unknown substances, this can also cause unnecessary stress for athletes as verbal assurances provide no guarantee and the athletes' focus should not be on antidoping procedures. Furthermore, a retrospective application for a TUE is not guaranteed to be approved and an appeal against the initial decision may add further time and stress to the process.

\section{Beneficence}

As evidence will be lacking for conventional and alternative treatments, it can be difficult to assess relative physical and psychological benefits or to provide sufficient antidoping evidence to support treatments. The required threshold of evidence for the treatment of rarer conditions would probably be arbitrary and based on standard medications for common conditions.

For an athlete with certain medical conditions (such as metastatic cancer, while undergoing various chemotherapy, radiotherapy treatments or major organ surgery) any performance advantage of potential banned substances or theoretical risk of contamination from supplements may be more than negated. Alternative and complementary treatments or supplements, which carry potential for failed antidoping tests, are commonly sought in cancer. Essential vitamin and mineral supplements correct clinical deficiencies and malnutrition brought about or exacerbated by the disease and treatments. Supplements can provide vital nutritional support when side effects, procedures or the disease make eating food extremely difficult. These may have similarly low levels of evidence base as accepted traditional medical treatments and yet do not seem to be viewed as sympathetically by antidoping agencies, despite the potential for medical, holistic, psychological and arguably placebo benefits. The inflexibility of antidoping rules when broadly applied regardless of circumstances could therefore ultimately confound optimal support and recovery for certain medical conditions.

It is an enormously beneficial and important principle for an athlete to remain available for competition, when undergoing life-saving treatment, regardless of their fitness or performance levels. There can be no athlete benefits to suggest temporary removal from competition in these circumstances, when hope and availability are themselves a treatment goal and fitness through sport/training an important part of the treatment plan. DT has proved, with his determination and positivity, that it is still possible to compete in sport at an elite level and regularly defy expert opinions and consensus. Unnecessary worry and discussions with such athletes about unknown risks of positivedoping tests are wholly avoidable. Furthermore, the very process of checking medications and applying for TUEs with national antidoping bodies draws unnecessary attention to an athlete who may then be targeted by the 'intelligent' approach to testing. For example, a trail blazed by one high-profile athlete's treatment of testicular cancer followed by considerable sporting success and an ultimate admission of long-term doping may cloud judgment in commonsense management of doping risks.

If athletes with cancer diagnoses made through antidoping tests were followed up, outcomes could be audited and lessons in care and processes could be learnt. Furthermore, an athlete peer 'group' could be formed allowing them to provide each other with support and expert guidance to face challenges and could even assist their medical staff. Good medical practice would also support vital follow-up of borderline clinical test results, where medical diagnosis is uncertain and antidoping rules have not been broken. It would be beneficial for this data to be published and made public if lessons are to be learnt.

\section{Non-maleficence}

Current procedures and processes can be challenging, psychologically detrimental and naturally stressful for an athlete and their family in extreme medical circumstances, at times when energy and effort should be focused on treatment, fitness and recovery. Concessions can be made, without fear of precedents being set in extreme medical circumstances, and this could be quickly facilitated by direct athlete medical team to antidoping medical expert communication channels being communicated 
and perhaps made public. Failing this, perhaps an independent athletes' ombudsman could act as an intermediary on sensitive antidoping matters. ${ }^{13}$

\section{Justice}

Current rigid application of rule processes cannot be fair for athletes in extenuating medical circumstances, where performance enhancement and fair competition are not possible and treatments carry potential exclusion risks or fear of exclusion. Just reassurances can only be given by independent medical experts and this process should be clear and prompt.

Clarity and improved communication channels are needed to ensure that athletes going through similar circumstances do not encounter similar antidoping challenges.

\section{CONCLUSIONS}

Physical fitness through sport improves health outcomes for many significant chronic diseases and cancers. When diseases are diagnosed through routine antidoping tests and systems challenged, urgent referral to expert medical panels would ensure the protection of ethics, protection of athletes' desire to compete, when sport and availability for coach selection, regardless of fitness, can become a fundamental motivation and component of disease treatment. In certain extreme medical circumstances precedent setting cannot be challenged on ethical, sporting or medical grounds. Use of accepted medical treatments, complementary and alternative medicines, both of which lack evidence, should not cause additional psychological stress or competing eligibility fears for an athlete, when even if they did result in a failed antidoping test, performance enhancement would be irrelevant. Decisions about which complementary and alternative treatments to pursue should not necessarily be determined by antidoping in these cases. Above all else, intention and desire to compete must be protected. Medical ethics and duty of care support centralised antidoping authorities following up athletes where cancer is diagnosed by routine tests, allowing outcomes to be audited and lessons learnt. Good medical practice would support vital follow-up of borderline antidoping test results, where medical diagnosis is uncertain and antidoping rules have not been broken.

The practice of sport is a human right. Every individual must have the possibility of practicing sport, without discrimination of any kind and in the Olympic spirit, which requires mutual understanding with a spirit of friendship, solidarity and fair play.Olympic Charter

Correction notice This paper has been amended since it was published Online First. An error was introduced by the production department at the bottom of the first page in the second column. The following sentence "DT, a co-author on this paper, failed a Dylan Tombides (DT) test..." has been corrected to "Dylan Tombides (DT), a co-author on this paper, failed an anti-doping test..."
Acknowledgements All the authors would like to thank West Ham United Football Club, their staff and athletes for unwavering support and well-wishes for DT during his fight against cancer. They would especially like to thank Dan Bernadin \& Greg de Carnys for their trailblazing to help DT achieve his sporting goals and assistance changing and shaping expert opinions. They would also like to thank Greg Whyte for his expert guidance in attaining fitness at critical times. They would also like to thank Professor Jiri Dvorak, FIFA Chief Medical Officer, for his immediate and sympathetic communication of DT's initial failed antidoping test, his expert advice and guidance through antidoping processes and his desire to find solutions relating to the content of this paper.

Contributors RW and DT conceived the idea. RW drafted the abstract for the consensus meeting and initial draft of this manuscript, and all authors contributed equally to the further review and improvements. All authors critically revised and approved the final version of the manuscript.

\section{Competing interests None.}

Provenance and peer review Not commissioned; internally peer reviewed.

Open Access This is an Open Access article distributed in accordance with the Creative Commons Attribution Non Commercial (CC BY-NC 3.0) license, which permits others to distribute, remix, adapt, build upon this work non-commercially, and license their derivative works on different terms, provided the original work is properly cited and the use is non-commercial. See: http://creativecommons.org/ licenses/by-nc/3.0/

\section{REFERENCES}

1 Matheson GO, Klugl M, Dvorak J, et al. Responsibility of sport and exercise medicine in preventing and managing chronic disease: applying our knowledge and skill is overdue. Br J Sports Med 2011:45:1272-82.

2 World Health Organization. Health and development through physical activity and sport. Geneva: WHO, 2003

3 Fong DY, Ho JW, Hui BP, et al. Physical activity for cancer survivors: meta-analysis of randomised controlled trials. BMJ 2012;344:e70.

4 Craft LL, Vaniterson EH, Helenowski IB, et al. Exercise effects on depressive symptoms in cancer survivors: a systematic review and meta-analysis. Cancer Epidemiol Biomarkers Prev 2012:21:3-19.

5 Fuller CW, Junge A, DeCelles J, et al. 'Football for Health'-a football-based health-promotion programme for children in South Africa: a parallel cohort study. $\mathrm{Br}$ J Sports Med 2010;44:546-54.

6 Blatter S. "FIFA President. Football for Hope." 2010. http://www.fifa.com/mm/ document/afsocial/footballforhope/51/56/34/footballforhopebrochureen_neutral.pdf

7 Matheson GO, Klügl M, Engebretsen L, et al. Prevention and management of non-communicable disease: the IOC consensus statement, Lausanne 2013. Br J Sports Med 2013;47:1003-11.

8 Dvorák J. Give Hippocrates a jersey: promoting health through football/sport. $\mathrm{Br} J$ Sports Med 2009:43:317-22.

9 Cowan DA, Houghton E, Jickells S. Clarke's analytical forensic toxicology. Drug Abuse Sport 2013:273.

102012 Anti-Doping Testing Figures Report. WADA. http://www.wada-ama.org/ Documents/Resources/Testing-Figures/WADA-2012-Anti-Doping-Testing Figures-Report-EN.pdf

11 Bernstein J, Perlis C, Bartolozzi AR. Ethics in sports medicine. Clin Orthop Relat Res 2000;378:50-60

12 Devitt BM, McCarthy C. 'I am in blood Stepp'd in so far...': ethical dilemmas and the sports team doctor. Br J Sports Med 2010;44:175-8

13 Moynihan L, Kate Hoey MP. Raising the Bar, Final Report of the Independent Sports Review. 2005 